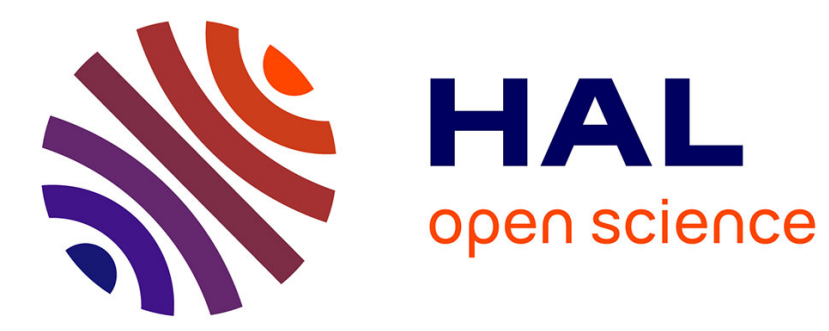

\title{
Collaborative Postgraduate Studies in Higher Education: A Case Study of South Africa
}

\author{
Francis Mungofa Manzira, Willard Munyoka
}

\section{To cite this version:}

Francis Mungofa Manzira, Willard Munyoka. Collaborative Postgraduate Studies in Higher Education: A Case Study of South Africa. 11th IFIP World Conference on Computers in Education (WCCE), Jul 2017, Dublin, Ireland. pp.134-148, 10.1007/978-3-319-74310-3_16 . hal-01762878

\section{HAL Id: hal-01762878 \\ https://inria.hal.science/hal-01762878}

Submitted on 10 Apr 2018

HAL is a multi-disciplinary open access archive for the deposit and dissemination of scientific research documents, whether they are published or not. The documents may come from teaching and research institutions in France or abroad, or from public or private research centers.
L'archive ouverte pluridisciplinaire HAL, est destinée au dépôt et à la diffusion de documents scientifiques de niveau recherche, publiés ou non, émanant des établissements d'enseignement et de recherche français ou étrangers, des laboratoires publics ou privés. 


\title{
Collaborative Postgraduate Studies in Higher Education: A Case Study of South Africa
}

\author{
Francis M Manzira and Willard Munyoka \\ University of Venda, Thohoyandou, South Africa \\ francis.manzira@univen.ac.za, willard.munyoka@univen.ac.za
}

\begin{abstract}
This research aimed to investigate the delivery of postgraduate study through incorporation of Google Applications and Skype technologies as collaborative tools. Participants were a cohort of full time working employees from a South African cohort of collaborating universities enrolled in the Post-Graduate Diploma in Higher Education course, located in Limpopo and Western Cape provinces. The data was collected through interviews from participants on Skype and Google technologies that include Google drive, Gmail, Google docs, Google spreadsheet, and Google chat. Data was analysed through ethnographic content analysis and conversational analysis. Based on the findings, it was evident that Google applications and Skype technologies support collaborative learning. The study results show that these technologies have an important role in future delivery of academic post graduate programmes in institutions of Higher Learning amongst working employees. This study recommends use of these technologies in scenarios involving multiple institutions across the world. Cloud computing has a pivotal role in enabling online collaborative learning activities and it enhances effective skills development in cases where students cannot afford to attend courses on full time basis due to work commitments or geographical location
\end{abstract}

Keywords: Google Apps, Collaborative applications, Cloud computing.

\section{Introduction}

Computer supported collaborative work systems plays a significant role in enhancing productivity in different work environments and strengthens the effectiveness of teamwork. Advances in Information and Communication Technologies have led to a significant change in the coordination of activities from across a wide array of industries. Technologies that are currently on the market affect cooperation and coordination in teams working on a given task. Application of then new technologies continues to enable new ways of working in the business environment.

Several research works in Computer Supported Collaborative Work (CSCW) point out that application and use of technology affects coordination and there is a need for social organisation of cooperative work which if not properly handled may lead to problems, [13, 14, 39]. The advances in Information and Communication Technologies coupled with reduced bandwidth costs have enabled transmission of real time data to any remote site across the world that will be connected on the network, $[3,16,17]$. 
CSCW are not only to be used for collaborative work purposes but they play a significant role in knowledge construction and also collaborative learning which is mainly facilitated through interconnectivity amongst participants involved. In addition, the new technological options available on the market also propel new types of knowledge management interactions that are based on micro-activities, $[1,9,15,16$, 17]. The main rationale of this study was to investigate the gap closure of newly available google technologies on collaborative delivery of a post graduate academic programme to students engaged as full time employees but are geographically dispersed. It was also the researchers' interest stemming from lack of empirical studies on the specific use of Google Educational Applications as a collaborative tool, in Higher Education., [28] argued in their research that there is still much to be investigated concerning the use of Google Educational Applications, which is often viewed as a much marginalised collaborative tool. As such it was of interest to have the study carried over a twelve months period. The students enrolled for the PostGraduate Diploma in Higher Education course were full time employees at a University in Limpopo province, and three Universities in the Western Cape Province. There were six facilitators working with the students for administrative and course delivery purposes. They formed part of the Google drive administrators who had the responsibility of group administration tasks. As such all the information exchanged and shared was confined to only participants enrolled for the programme and had Gmail accounts. Students were using the Google applications in their communication, collaboration, information sharing and problem solving on group tasks allocated by the facilitators during the study. In addition, Skype and institutional emails were also being used to ensure effective delivery of intended message to the participants.

The study aimed to address the following research questions:

1. Can Google applications and skype enhance collaboration among full time employees to advance higher qualification studies?

2. How effective are Google applications and skype technologies in higher education academic collaboration?

\section{Literature Review}

\subsection{Array of collaborative software features}

There is a broad array of commonly used software applications in collaborative activities. Some of the most sought after features to consider for technology adoption include the following capabilities: Wikis, Web publishing, Calendaring software, Workflow system, Document Management, Discussion, Blogs, Surveys, Time Tracking, Charting, Bookmarking, Tagging, Rating and Comments Social software, Office suite.

These multiple features of software products have contributed towards increase in the use of collaborative software as they present tangible and intangible benefits to organisations. They determine activities that each product can support or not as various activities executed in a collaborative environment. Information sharing, communication and coordination are three main categories of why people engages in 
real time or asynchronous collaboration although other activities such knowledge creation, archiving or storage occurs simultaneously, [4, 9, 11, 16, 17, 22]. [32] focused on a case study on rapid adoption of data conferencing in a large corporation where minimum technical support was provided with no management mandate. [8] identified three important features of interaction that are central to successful collaboration as namely: intimacy among participants, rich supply of external resources, such as computers, and histories of joint activity of those interacting.

\subsection{Google Applications for Work}

Google Apps has become one of the most powerful communication and collaboration tools used in personal and business environments across the globe. It can be accessed via the web, so everyone can connect with everyone else, regardless of geographic location. Google apps are considered to be secure as access is only granted to people registered with the Google domain through username and password for login purposes, [27]. The apps are flexible, easy to use and web based as there are no installation or maintenance costs involved in the process, [29]. In addition, because of the reduction costs of internet services couple with improved infrastructure and bandwidth, people can easily access the services at affordable costs. As cloud computing matures, several organisations are offering Software as a Service (SaaS) platform where a wide range of cloud based applications that can be used by businesses, governments, non-profit making organisations and individuals, [38]. Table 2 shows four categories into which Googles apps can be classified, namely communication, storage, collaboration and administration. Various applications in each of the categories makes it one of the most preferred in academic environment and as a free edition, it helps organisations with inadequate resources to significantly reduce installation, maintenance and licensing costs, [12]. According to [35], the emphasised the need by participants involved to uniformly adopt the same technology across for tasks at hand. Cloud computing provides google with such a powerful advantage since a browser with internet connectivity are required thus rendering it free from operating systems platforms. The storage in google cloud is provided free of charge to the users and security is guaranteed as the services can be accessed using a user name and password. Data security is guaranteed as it cannot be accessed by any person other than the account holder.

\subsection{Cloud Computing in Higher Education}

The changing technologies on the market have resulted in the need to adjust interaction and collaboration amongst participants working in geographically dispersed environments. The paradigm of cloud computing has created the enabling environment which has resulted in people being globally connected through the cloud, for instance use of emails such as Gmail, Yahoo, Office365 or Hotmail [27]. Continuous grown and improvement of cloud technology has led to widespread adoption of cloud services in different institutional activities. In addition, considered as benefits of such adoption identified by [4, 5,18, 36, 37], as: Increasing interoperability between disjoint technologies between and within institutions, Driving down the capital and total costs of IT in higher education, facilitating the transparent matching of IT demand, costs, and funding, it offer users and 
organizations convenient access to computing without having to understand the intricacies of exactly how processing is performed within the cloud, achievement of large-scale efficiencies without sacrificing performance. Cloud computing service providers are offering higher education institutions, the opportunity to substitute their existing data centres, servers, applications and replacing the traditional campus machines with data and information in the cloud, [20, 36].

\section{Research Design}

In this study, the Google Applications were introduced as collaborative platform to support group work from the inception of the course. In addition, there quarterly blocks for one week period in which participants would converge with the facilitators to wrap up on the assigned activities and present progress of assigned tasks. For the purpose of this study, there were twenty-four participants involved together with six facilitators. However, there was no need for classes on how to use the Google Applications although majority of the participants were not familiar with them. They had knowledge of internet technology, with other already using Gmail accounts for personal communication. The Google drive was the repository on cloud where all data was accessed. In addition to Google applications, Skype and personal institutional electronic mails were used to ensure that communication process was effective. Skype was mainly used for video conferencing by the participants when the need for meetings arose or in case one of the participants had an urgent matter that may require the facilitator to demonstrate practically or any of the participants to be engaged.

\subsection{Method}

The research adopted action research since the participants were actively involved in the programme over a twelve months period. "Action research aims to contribute both to the practical concerns of people in an immediate problematic situation and to the goals of social science by joint collaboration within a mutually acceptable ethical framework" [33]. According to [24], the strength of action research is in its focus on generating solutions to practical problems. It has the ability to empower practitioners through enabling engagement with research aspect and the subsequent development or implementation activities. [20] maintains that Action research is participative and collaborative which is enable the participants of the post-graduate studies who had a common purpose, to solve group assignments, contribute in paper writing, evaluation of individual activities and projects. The participants involved were draw from a wider experience in the process of collaboration through google technologies and skype. Meetings were contacted at stipulated intervals through skype which enable even conferencing calling. Minutes of the meetings would then be noted for reference purposes by the participants. Data was collected through structured interview. The interview allows obtaining of concrete, rich data through applying investigational perspective that was supported from research works of [7]. Standardised open ended questions were asked from participants with tape recording of the interview and notes taking simultaneously. The open-endedness allows the participants to contribute as much detailed information as they can and enables the researcher to ask probing questions as a means of follow-up [10]. 


\subsection{Data Analysis}

Having adopted action research, the inquiry therefore follows ethnographic content analysis as proposed by [2]. Rather than focusing entirely on statistical analysis of frequencies of identified themes in the content analysis, ethnographic content analysis involves a "reflexive analysis of the documents," and website conversations, [5]. Furthermore, this approach is used for studying reflexions of products in social interactions, and to comprehend the analysis of group participants in relationship to other group members in the online Google collaborative learning environment. [2] suggests that ethnographic content analysis is the most suitable data analysis technique when the objective of the results of the research are "commenting and narrative description" (p.67), and for this reason the researchers decided to use this analysis technique to realize the aim of this research.

Content analysis emphasises the identification of different groups and sub-groups of content on studied concepts; and this can be achieved through either manual or automatized codification of online conversations, commenting, documents, interviews, or any other written information. Member checking was used to ensure validity of the results through sending the recorded responses to ensure validity and trustworthiness of the qualitative research results. Participants had the opportunity to review the accuracy of their statements that were recorded before the results were finalized. It is a process that ensure quality control of results as errors are eliminated before final publishing [7]. The researchers used thematic analysis, and identification of sub-themes in the online Google collaborations amongst the participating students and facilitators; guided by a set of formulated research questions (serving the purpose of major guiding themes) as proposed by [2]. Additionally, the study implemented the five key-processes of content analysis proposed by Krippendorf [21], Defining the analysis unit, Sampling, Reduction, Deduction, Narration/Discussion. The next section outlines result findings for this research.

\section{Results}

Analysis of data collected from participants revealed that participants did benefit from use of Google Applications for the tasks that had been assigned. Given the fact that they were geographically apart, they managed to communicate, share and create knowledge in the process.

\subsection{Real time collaboration}

As the participants were geographically apart, it was not feasible that every time a meeting had to be done, people should meet. This concur with [24] who argued that online face-to-face discussions are invaluable in collaborative tasks and decisionmaking processes schedule where there are time, space and distance constraints. The respondents below agreed that Google applications provided them with the opportunity to work in a real-time environment as you can be able to simultaneously work on a document. Participants could easily see who was working on what section because when another participant makes an edit, their change will automatically 
appear on your screen when you are viewing the file, with their name next to their cursor so that you can see who is typing.

QUESTION 1 - What were the benefits of using google drive for the assigned tasks allocated to you?

R1"Google drive - collaborative work, working together in "real time", chat and comment features for feedback, can all work on one document at the same time, sharing of articles/books".

R2 "Google Drive has more affordances as there are many tools in the suite which can be used for co-writing, giving and receiving feedback, making changes to documents, either synchronously or asynchronously".

R3 "You can edit a file at the same time with other colleagues regardless of distance, only internet connection is required. For instance, we managed to prepare a power point presentation for our next block session and trimmed to the right size since we were virtually together during the preparation"

R4 "When you are working on a document concurrently with other in the same space, you can chat with the participants viewing the document so that you don't have to email back and forth while you work. Anyone viewing the document and signed in to a Google Account will be included in the chat."

\subsection{Video Conferencing}

Participants needed to meet in the virtual environment for issues pertaining to meetings, allocation of tasks and provision of feedback. This was facilitated through using skype which has a broad range of features, including instant messaging, free voice and video conferencing, its ability to use peer to peer. The use of quality videos fosters collaborative design, teamwork coordination, interactive discussions, and sharing of knowledge as participants feel involved in the activities. The responses below led to the conclusion that skype is a convenient mode of communication where distance appears to be a barrier and time constraints. Besides being used for conferencing, [24] identified that Skype can be used to conduct interviews or focus groups in real time via the instant messaging feature, which allows multiple users to participate simultaneously by typing their comments in a common virtual room. Thus, it is a useful data collection tool for textual, audio and visual data.

QUESTION 2 - How convenient was Skype for the conferencing in your meetings and other tasks?

R1"Skype provides opportunities to interact in real time seeing the person's face or just talking so that ideas can be clarified, people can interact in groups across geographical distances. It also has asynchronous affordances in the form of written messages offered through instant messaging service”.

R2"Skype allows for communication to occur in real time. We managed as a group to create repositories of data in google drive for our tasks and the paper which the developed focusing on connectivism. The feedback process is more dynamic and colleagues assisted each other on a continuous basis either through voice calling with video or instant messaging services"

R3” This is a very good group interactive video chat application with immense benefits that if was possible to deliver my course to students without being in class, I would have opted for such. In our case the group video chat enabled us to see and 
chat with each other on a single screen at the same time. It is possible that in the event of strong bandwidth, this tool can be used to address groups in large scale projects”.

R4" The immediacy of being able to share information, thoughts and knowledge. Real time discussions can be held with several people even though they are not in the same location. So, the geographical barrier is removed. Also, non-real-time communication is possible by reading replies and responses at a later stage. Also, time is no longer an issue as one can communicate and work 24/7.I also think that if the group vibe is positive, the motivation and group dynamics can be greatly enhanced by the "social" part of using social media. So, it allows for personal interaction, which can be used to sustain and motivate the work ethics."

\subsection{Technology experience and future plans}

New experiences with technology will develop learning capabilities and rethink on future course of action on how tasks can be reorganised. Participants expressed greatest enthusiasm after first encounter with google and skype technologies. It is of great importance that participants"' mind-set had been refocused especially on how to harness technology in their future endeavours within the career and work places.

QUESTION 3 - After your experiences with Google technologies and Skype, are you prepared to incorporate them in your future work projects in higher education?

R1"Definitely yes: I find Google Drive to be most useful for the actual writing and giving and receiving more extensive feedback. The fact that people can write simultaneously across geographically distant contexts is a great affordance for collaborative work. It was interesting that we managed to work on a group conference paper as team through these technologies, I couldn't imagine it, great.”

R2"I have been using them socially but after this experience of formal setting, I do plan to incorporate it in the next collaborative tasks, be it on a local research or international research projects as the concept of collaboration cannot be isolated from the from the ever-growing Information and communications technologies that are the backbone".

R3” I find Google Drive to be most useful for the actual writing and giving and receiving more extensive feedback process during conference paper production. The fact that people can write simultaneously across geographically distant contexts is a great affordance for collaborative work. Because these tools increase communication, generally the effective component of online learning is heightened and people become more vested and involved in task execution. These technologies also provide opportunities for formal interaction in a professional environment and for more personalised communication".

R4"As we continue to develop new Master degree programmes in our faculty, I believe this will be the best tool to interact with post graduate students pursuing research work, as the students can utilise Google Drive to deposit work in progress and completed tasks, I addition these applications enables virtual power point presentations. Due to increasing demand in the industry and wide adoption of technologies, this can assist the institution to capture a market of our own for employees in full time employment. Although face to face meetings cannot be completely eliminated, travelling, accommodation costs and lost time are drastically reduced." 


\subsection{Apps challenges}

The reality of the applications in any workspace is that they require internet connectivity. Unlike global positioning systems they do not operate with satellite technologies. Poor internet connectivity is a major setback in successful collaboration with the apps. From the responses recorded, it is evident that South Africa as a developing country, it still has challenges in terms of providing low cost mobile networks data and strength of the signals. [16] explained that video chat requires realtime communication and if the application over utilizes the link, it causes unfairness to other traffic and if it under-utilizes the link, it may cause low quality of video chat. Thus, with mobile devices, the uplink-downlink connection in 3G is asymmetric as the bandwidth is greatly determined by network signal strength in a given geographic area. For instance, it is stronger in urban areas and as you radiate to the outer peripherals it becomes weaker.

QUESTION 4 - What were the main challenges associated with using Google Apps and Skype you encountered in you activities?

R1"When using mobile networks for internet connectivity on mobile devices such as iPad, smart phones and laptops, the bandwidth provided by mobile network service providers is sometime slow.

Cost of data bundles is a bit high since you are using voice integrated with a camera which demand high data volumes on mobile networks"

R2"Connectivity and associated cost of data transfer is always an issue .With a slow internet connection (mobile or land line) it's almost impossible to use this form of media interaction. Also data remains expensive; especially on mobile apps this greatly limits the applicability. Especially something like Google docs or presentation can be very data intensive".

R3 "Google Drive - sometimes is a bit slow when working on a presentation live. In this instance it was a new system to get to learn which was time consuming and challenging for a non-technologically minded person! With Skype it's not always easy to get a good video due to internet connection.

R4"I did not encounter major challenges besides failure to connect with other colleagues who internet connectivity problems in some instances. Our institutional systems are quite stable and significant investments have been made in technological infrastructure."

\subsection{Conversational analysis}

The conversation in Figure 1 shows a brief exchange of messages by the participants when they were working on a group conference paper. Minutes of activities that were involved in the process are outlined in the below section. According to [34], conversational analysis (CA) aims to 'describe, analyze, and understand talk as a basic and constitutive feature of human social life'. Conversation is the main way in which people gather or collaborate, exchange information, negotiate and maintain social relations [29]. [37] research findings analysis of data related to interactions in on line revealed that on line chat exhibits features of turn-taking, repair and adjacency pairs as important concepts in CA. These principles are deemed to be effective in the situation of online chat whereas a variation from what we would expect to find in face-to-face conversation can be noted. The extract in Figure 1 shows synchronous communication between participants during the period of introducing connectivism as 
part of group tasks that were involved. Participants were regularly exchanging messages that would contribute towards executing the assigned task.

\subsection{Discussion topic: Introducing Connectivism}
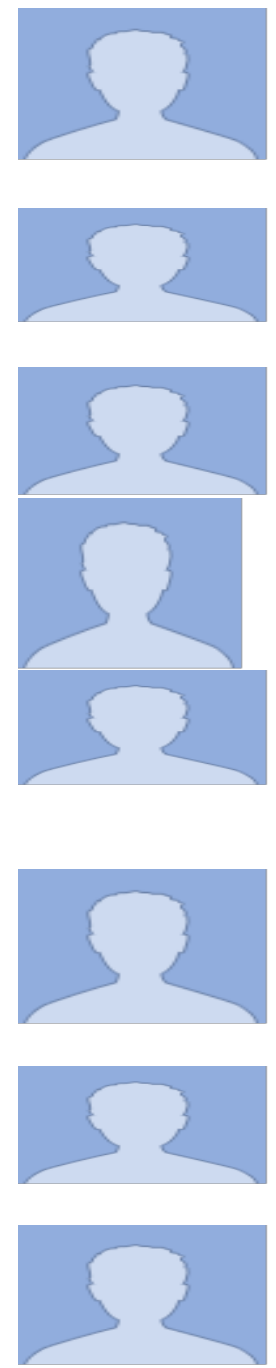

\section{Participant A}

all your statements need to be evidence-based (i.e. followed up with references so that the reader can follow where you have got these ideas

\section{Participant B}

So for instance if you make a statement have a ref (Siemens, 2008) to back it up

\section{Participant C}

$\mathrm{Hi}$, are you referring to the matrix? any specific point?

\section{Participant A}

most sections besides yours

\section{Participant C}

Hi thanks again for the super helpful feedback.

I am already working on the corrections. Will read a bit more before making the changes

\section{Participant C}

We will keep you up to date :)

\section{Participant D}

I will do so. Can I say that Concept of learning is

"the idea of practising connectivism and reflecting on such practice".

\section{Participant D}

Marked as resolved

Fig 1: Google chat conversational text

\subsection{Minutes of a meeting coordinated at Facilitator's office through Skype video conferencing}

This section shows the minutes of a meeting that was conducted through Skype conferencing by the participants and facilitator who were geographically located at the universities in two provinces respectively. The meetings held lasted for a period of forty minutes minimum and one hour maximum. Tasks were organised and allocated according to the participant's background that was decided through input of what 
each participant considered being stronger in. Execution of the tasks would then precede through Google Applications after the allocation of tasks during the meetings.

Present: Participant A, Participant B, Participant D, Participant E, Participant F, (Skype), Facilitator

Introduction to connectivism - Participant A

Literature review on social media - few slides - Participant D

Methodology - auto ethnography -Participant F

Comments on google drive - Facilitator will look at the role of the facilitator. Social interaction - looks at various aspects of connectivism and look for when it happened. Google chats, Actual presentation.

What's App conversations - Participant B

Emails, Looking at nodes of connectivism

- maybe c-map

Findings - Participant C

The role of the facilitator - how much did the facilitator adhere to the role of a connectivist facilitator? What are the pros and cons of using connectivist ways of learning?

Creating the knowledge using the basis of a theory

How did we use connectivist knowledge?

Participant B \& E .thought that they spent a lot of thinking time - hours and hours - social interaction is intertwined with academic aspects. Personality dynamics are more important here - you tend to say more things than if you were sitting around the table, we need to analyse why certain group members were connected and worked together and why others did not participate. What were the effects on both the connected and disconnected members and what was the impact on the learning process and the product?

\section{Conclusion and future work}

It is possible that cloud computing enhances any form of online education although this research was focusing on full time employees who were attending block sessions of the course in specified times of the year and complementing other course related activities using cloud computing. Cloud computing tools enables dynamic group work approach and presents the opportunity for motivation and self-responsibility of students. They enable sharing and working on documents simultaneously irrespective of the geographical location of students, internet is the backbone technology required amongst the connecting parties involved in the learning process. It is important to note that Google applications as part of Computer-Supported Collaborative Work Systems are not just useful for the purposes of collaborative work. They are more critical on collaborative learning. A tremendous shift towards cloud computing is enabling institutions of higher learning to reduce expenditure on information and communication technologies and capitalize on the low-cost maturing technology available on the market. This article presents the potential of integrating two concepts, namely those of a virtual interactive room and a web-based collaborative work application in order to enhance knowledge construction and removing the barriers of distance encountered by working class, [14, 20, 26]. From responses obtained during the study, we can conclude that cloud computing through use of Google Applications 
and Skype technologies effectively facilitated collaboration amongst the participants who were involved in the study. Although they were operating from a distant, there was an achievement in executing the give tasks, knowledge sharing, building, communication and coordination. However, this study recommends use of these technologies in scenarios involving multiple institutions across the world.

\section{References}

1. Ackerman, M.S., Dachterai, J., Pipek ,V., and Volker,V.: Sharing knowledge and expertise: The CSCW view of knowledge management. Computer Supported Cooperative Work (CSCW) 22, (4-6), 531-573 (2013)

2. Altheide L. D.: Ethnographic Content Analysis. Qualitative Sociology, 10, 65-77(1987)

3. Bayerl P. Saskia and Kristina, L.: Technology Effects in Distributed Team CoordinationHigh- Interdependency Tasks in Offshore Oil Production. Computer Supported Cooperative Work (CSCW), 19(2), 139-173(2010)

4. Bin, Y and Xinying,R.: “Construction of 'Cloud Services’ Ring System in Higher Education,” Software Guide · Educational Technology, pp.93-95, (2011)

5. Butnaru I. Gina.: The method of ethnographic and content analysis in determining development factors of economic and managerial tourism Performance. Procedia Economics and Finance, 20, $104-111(2015)$

6. Cloud 101.: Developing a cloud computing strategy for higher education". (2012). White paper, http://www.cisco.com/c/dam/en/us/solutions/collateral/collaboration/ cloudcollaboration/cloud_101_higher_education_wp.pdf. , last accessed on 2017/01/20

7. Creswell,J.W.: Qualitative inquiry \& research design: Choosing among five approaches (2nd ed.). Thousand Oaks, CA: Sage(2007)

8. Crook, C.: Children as computer users: the case of collaborative learning. Computers and Education, 30, 237-247 (1998)

9. Eseryel, D., Ganesan, R., and Edmonds, S. G.: Review of Computer- Supported Collaborative Work Systems, Educational Technology \& Society 5 (2), (2002)

10. Gall, D., Meredith, G., Joyce,P., and Borg, R.W.: Educational research: An introduction (7th ed.). Boston, MA: A \& B Publications (2003)

11. Ganesan, R., Edmonds, S., Gerald, S., and Spector, J. M.: The changing nature of instructional design for networked learning (2002) In Networked learning: Perspectives and issues, Springer London, 93-109.

12. Google Inc.: Google Apps for Education. Available at: http://www.google.com/apps/edu. (2012b), last access 2017/01/10.

13. Harper,R.R., Hughes. A. J., and Shapiro, Z. D.: Working in harmony: An examination of computer technology in air traffic control. In EC-CSCW '89. Proceedings of the 1st European conference on computer-supported cooperative work, Sloug, UK, September 13 to 15, New York: ACM, pp. 73-87(1989)

14. Heath, C., and Luff, P.: Collaboration and control: Crisis management and multimedia technology in London underground control rooms. Computer Supported Cooperative Work, 1(1), 69-94 (1992)

15. Hernandez-Serrano, J, Choi, I., and Jonassen, H.D .: Integrating constructivism and learning technologies. Springer Netherlands, In Integrated and holistic perspectives on learning, instruction and technology. 103-128 (200)

16. Jana, S., Pande., A., Chan, A. J., and Mohapatra, P.: Mobile video chat: issues and challenges. Communications Magazine, IEEE 51, (6), 144-151(2013)

17. Jian, L,: “On Computer-supported Collaborative Learning Under the Support of Cloud Computing, Journal of Jixi University,” vol. 11, pp.5-6, (2011).

18. Jonathan, G., and Poltrock., S.: Computer Supported Cooperative Work. In: Soegaard, Mads and Dam, Rikke Friis (eds.). "The Encyclopedia of Human-Computer Interaction, 
2nd Ed.". Aarhus, Denmark: The Interaction Design Foundation (2014). Retrieved February 122017 from https://www.interactiondesign.org/encyclopedia/cscw_computer_supported_cooperative_work.html.

19. Katz, R., Goldstein, P., and Yanosky, R.: Cloud Computing in Higher Education, Educause (2009). Retrieved January 152017 from http://net.educause.edu/section_params/conf/CCW10/highered.pdf.

20. Koshy, E., Koshy, V., Waterman and Heather.: Action research in healthcare, Sage, 1-24 (2010)

21. Krippendorff, K.: Reliability in Content Analysis: Some Common Misconceptions and Recommendations. Human Communication Research, 30(3), 411-433 (2004)

22. Luna, W. and Sequera, J.L.C.: Collaboration in the Cloud for Online Learning Environments: An Experience Applied to Laboratories. Creative Education, 6(13), p.1435. (2015)

23. Mathew, S.: Implementation of Cloud Computing in Education - A Revolution, International Journal of Computer Theory and Engineering, 4(3), 473-475 (2012)

24. Mavengere, N., and Ruohonen, M.: "ICT4D 2.0 studies in virtual environment: Context and user needs to foster learning process,” IST-Africa Week Conference, 2016, (2016)

25. Meyer, J.: Using qualitative methods in health-related action research, British Medical Journal, 320, 178-181(2000)

26. Moylan, A. C., Derr, S. A., and Lindhorst,T.: Increasingly mobile: How new technologies can enhance qualitative research, Qualitative Social Work, 14(1), 36-47. DOI: 10.1177/1473325013516988 (2015)

27. Muuro,F., Wagacha,P., Oboko,R., and Kihoro,J.M.: “Students’ Perceived Challenges in an Online Collaborative Learning Environment: A Case of Higher Learning Institutions in Nairobi, Kenya,” Int. Rev. Res. Open Distance Learn., vol. 15, (2014)

28. Nevin,R.: Supporting 21st century learning through Google Apps. Teacher Librarian, 37(2), 35 (2009)

29. Okuhara,M., Shiozaki,T., and Suzuki, T.: Security architecture for cloud computing, Fujitsu Sci. Tech. J, 46(4), 397 -402 (2010)

30. Paliktzoglou, V., Stylianou, T., and Suhonen, J.: Google Educational Apps as a Collaborative Learning Tool among Computer Science Learners. Assessing the Role of Mobile Technologies and Distance Learning in Higher Education, 272 (2014)

31. Paltridge,B.: Discourse Analysis. An Introduction. London: Continuum (2006)

32. Poltrock, S., and Mark,G.: Groupware adoption in a distributed organization: transporting and transforming technology through social worlds, Information and Organization (14), 297-327(2004)

33. Rapoport, N.R.: Three Dilemmas in Action Research, Human Relations, 23(6), 499-513 (1970)

34. Scheid E. J., Minato, L., H., de Oliveira, S.B., Charão, A.S.: Cloud computing with Google Apps for education: An experience report, Journal of Applied Computing Research, 2(2), 60-67(2012)

35. Sidnell, J.: Conversation analysis: An introduction, UK: Wiley-Blackwell (2010)

36. K. Van der Schy and E.M.K. Kraussy. Higher education cloud computing in South Africa: Towards understanding trust and adoption issues, SACJ No. 55, 40-55(2014)

37. Wigdor, D., Shen,C., Forlines,C., and Balakrishnan,R.: Table-centric interactive spaces for real-time collaboration." In Proceedings of the working conference on Advanced visual interfaces, 103-107(2006)

38. Zaferanieh,E.: Conversation Analysis of Online Chat, Department of English, Mashhad Branch, Islamic Azad University, The First Conference on Language Learning \& Teaching: An Interdisciplinary Approach, October 30 - 31, 1-9 (2012)

39. Zuboff, S.: In the age of the smart machine: The future of work and power. New York: Basic Books (1988) 